\title{
PENINGKATAN LITERASI SISWA SMK PADA BIDANG-BIDANG AKUNTANSI DAN JENIS-JENIS PROFESI AKUNTANSI
}

\author{
${ }^{1}$ Rachma Agustina, ${ }^{2}$ Dwi Ari Pertiwi, ${ }^{3}$ Meta Ardiana, ${ }^{4}$ Deasy Ervina, ${ }^{5}$ Winaika Irawati \\ 1,2,3,4Program Studi Akuntansi, ${ }^{5}$ Program Studi Manajemen, Universitas Hasyim Asy'ari Tebuireng Jombang \\ ${ }^{1}$ rachma.agustina1@gmail.com
}

\begin{abstract}
Many different professions in the world of work can provide a variety of choices for each student to choose to enter the world of work in which they are interested. The urgency of this activity is carried out to explore and at the same time provide provisions for students who are studying in vocational high school majoring in accounting about the various fields of accounting and a picture of the future that they can achieve and take. Community service activities are carried out at SMK Palapa Ngoro Jombang, on 22 and 23 November 2019. The service methods are delivered with lectures, questions and answers and interactively with the participating students. After this service program is implemented, students can get an overview of the various fields of accounting and the accounting professions that they can later choose.
\end{abstract}

Keyword: Literation, fields of accounting, accounting professions

\begin{abstract}
Abstrak
Banyak ragam profesi dalam dunia kerja bisa memberi berbagai macam pilihan untuk setiap siswa memilih terjun ke dalam dunia kerja yang diminatinya. Urgensi kegiatan ini dilakukan untuk menggali sekaligus memberikan bekal pada siswa-siswa yang sedang menempuh pendidikan di SMK jurusan akuntansi tentang macam-macam bidang akuntansi dan gambaran masa depan yang bisa mereka raih dan tempuh. Kegiatan pengabdian kepada masyarakat dilaksanakan di SMK Palapa Ngoro Jombang, pada 22 dan 23 November 2019. Metode pengabdian disampaikan dengan ceramah, tanya jawab dan interaktif dengan siswa peserta. Sesudah dilaksanakan program pengabdian ini siswa bisa mendapatkan gambaran tentang berbagai macam bidang akuntansi dan profesi - profesi akuntansi yang kelak bisa dipilihnya.
\end{abstract}

Kata Kunci : Literasi, Bidang-Bidang Akuntansi, Profesi Akuntansi.

\section{PENDAHULUAN}

Jurusan Akuntansi merupakan salah satu jurusan di SMK yang cukup banyak mendapatkan respon positif dari masyarakat, sehingga bisa mendapatkan jumlah siswa yang signifikan. Ketertarikan wali murid dan siswa sendiri tentunya tidak lepas dari gambaran masa depan lulusan setelah mengikuti proses pembelaran di sekolah. Akuntansi dalam proses pembelajaran bias diartikan sebagai serentetan prosedur belajar yang memiliki tujuan untuk peserta didik agar mampu menerapkan metode akuntansi sesuai dengan kaidah keilmuannya. Peserta didik juga diharapkan paham tentang kepentingan akuntansi sebagai bahasa bisnis untuk mengambil keputusan untuk menjaga kelangsungan hidup suatu entitas, kemudian menyusun accounting report sesuai standar kompetensi yang telah ditetapkan. Proses belajar dalam akuntansi dilaksanakan dengan penerapan dukungan strategi belajar agar aktivitas pembelajaran berlangsung secara efisien dan efektif (Dwiharja, 2015).

Perkembangan dalam dunia usaha dan pendidikan diimbangi dengan perkembangan jenis-jenis bidang akuntansi, seperti akuntansi biaya, akuntansi manajemen, auditing, akuntansi perpajakan, akuntansi sektor publik, sistem informasi akuntansi, akuntansi keperilakuan dan perkembangan terakhir khususnya di Indonesia adanya konsep akuntansi syariah (Rombe, 2016). Beragamnya bidang-bidang akuntansi otomatis diikuti bertambahnya ragam profesi akuntansi, semisal adanya praktik akuntansi managemen 
ditimbulkan oleh kebutuhan managemen selain untuk kebutuhan pemegang kepentingan eksternal organisasi (Nahartyo dan Utami, 2015). Keberagaman profesi dalam dunia kerja memberikan pilihan bagi setiap siswa untuk memilih terjun ke dalam dunia kerja yang diminatinya. Selepas menempuh pendidikan, siswa-siswi yang mengambil jurusan akuntansi seharusnya sudah memiliki alternatif pilihan karir yang bisa dijadikan langkah awal untuk menentukan profesi yang ingin diterjuninya. Hal pertama yang bisa dijadikan pilihan adalah langsung masuk dalam dunia kerja setelah selesai menempuh pendidikan di SMK. Yang kedua, dapat melanjutkan pendidikan ke jenjang sarjana, baik sarjana ekonomi akuntansi maupun lainnya. Masih banyak terjadi kegamangan pada siswa-siswa ketika mulai mendekati masa kelulusan tentang masa depan mereka. Perlu keyakinan yang kuat dan kemantapan hati ketika memutuskan untuk mengambil langkah. Urgensi kegiatan ini dilakukan untuk menggali sekaligus memberikan bekal pada siswa-siswa yang sedang menempuh pendidikan di SMK jurusan akuntansi tentang gambaran masa depan yang bisa mereka raih dan tempuh. Sehingga ketika mereka lulus sudah bisa menentukan akan kemana cita-cita mereka nantinya.

\section{METODE}

Pola penyelesaian masalah tampak pada skema pelaksanaan dan alur pikir di bawah ini:

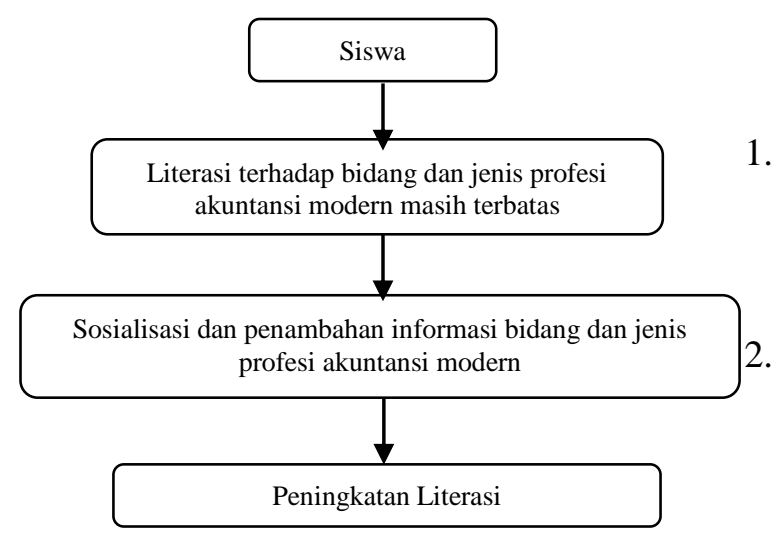

Gambar 1. Skema Pelaksanaan Program PKM Peningkatan Literasi

Untuk melaksanakan pengabdian masyarakat, Universitas Hasyim Asy'ari mempunyai pakar yang kompeten dalam berbagai disiplin ilmu yang berkaitan dengan permasalahan yang sedang diselesaikan. Untuk kegiatan ini juga melibatkan 5 (lima) orang mahasiswa yang saat ini sedang menempuh pendidikan di Prodi Akuntansi Universitas Hasyim Asy'ari Tebuireng Jombang, serta beberapa dosen sebagai berikut:

Tabel 1. Dosen Pelaksana Program PKM

\begin{tabular}{|l|l|l|}
\hline No & Nama Dosen & $\begin{array}{l}\text { Bidang } \\
\text { Kepakaran }\end{array}$ \\
\hline 1 & $\begin{array}{l}\text { Rachma Agustina, } \\
\text { M.Pd., M.Ak. }\end{array}$ & Akuntansi \\
\hline 2 & Dwi Ari Pertiwi, M.M. & Akuntansi \\
\hline 3 & Meta Ardiana, M.Pd. & Akuntansi \\
\hline 4 & Deasy Ervina, M.Ak. & Akuntansi \\
\hline 5 & Winaika Irawati, M.Pd. & Manajemen \\
\hline
\end{tabular}

Tabel 2. Mahasiswa Pelaksana Program PKM

\begin{tabular}{|l|l|l|}
\hline No & Nama Mahasiswa & $\begin{array}{l}\text { Program } \\
\text { Studi }\end{array}$ \\
\hline 1 & Rizal Asrifin & Akuntansi \\
\hline 2 & M. Galih Sidqi Muttaqi & Akuntansi \\
\hline 3 & Dara Puspita Solicha & Akuntansi \\
\hline 4 & $\begin{array}{l}\text { Waalfa Maegadur } \\
\text { Rohmatin }\end{array}$ & Akuntansi \\
\hline 5 & $\begin{array}{l}\text { Sulthan Fahmi } \\
\text { Risnanto }\end{array}$ & Akuntansi \\
\hline
\end{tabular}

\section{HASIL DAN PEMBAHASAN}

Hasil Kegiatan Pengabdian Kepada Masyarakat adalah sebagai berikut:

. Kegiatan PKM telah dilaksanakan pada hari Jumat dan Sabtu, tanggal 22 dan 23 November 2019, bertempat di SMK Palapa Ngoro, Ngoro, Jombang.

Materi yang disampaikan meliputi:

- Bidang-Bidang Akuntansi

- Profesi Akuntansi

- PPh pasal 21 
3. Jumlah peserta sebanyak 46 siswa, terdiri dari siswa kelas X dan XI.

4. Siswa tampak antusias dan aktif selama proses pemberian materi dan tanya jawab, karena :

a. Materi-materi yang disampaikan relevan dengan jurusan yang mereka pilih saat ini,

b. Penting untuk menentukan masa depan mereka sesudah selesai menempuh pendidikan di SMK.

\section{Luaran Kegiatan}

Adapun Luaran yang dicapai dalam Kegiatan Pengabdian Kepada Masyarakat adalah sebagai berikut:

\section{Luaran Wajib}

Prosiding Seminar Nasional. Seminar Nasional telah dilaksanakan pada 3 November 2019, SAINSTEKNOPAK Ke-3 dan Call For Paper, diselenggarakan oleh Unhasy Tebuireng Jombang dan bertempat di Aula Gedung Yusuf Hasyim Tebuireng, Jombang. Prosiding sedang dalam proses penerbitan, sertifikat peserta terlampir beserta artikel yang dikirimkan.

2. Luaran tambahan:

Rencana submitted di Jurnal Abidumasy

Unhasy Tebuireng Jombang.

Dokumentasi Kegiatan

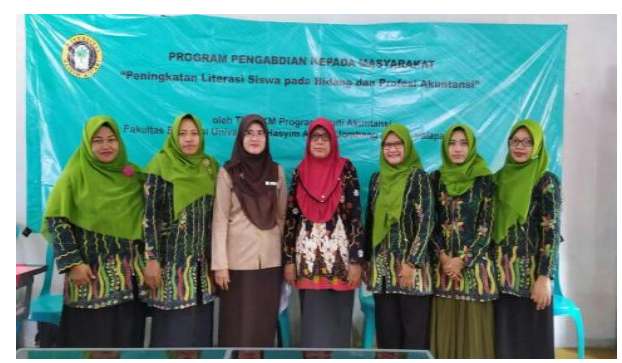

Gambar 1 Pemateri bersama dengan Kepala Sekolah SMK Palapa Ngoro, Jombang

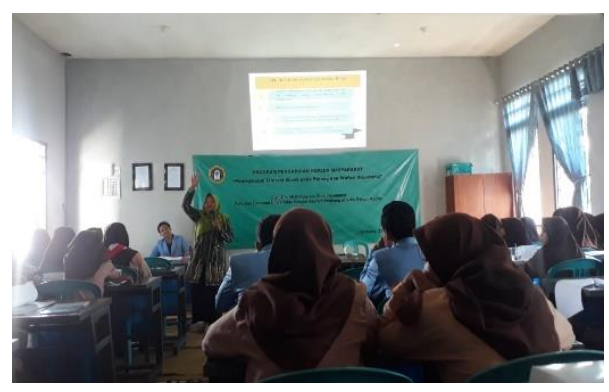

Gambar 2 Pemateri memberikan sosialisasi kepada siswa SMK Palapa Ngoro

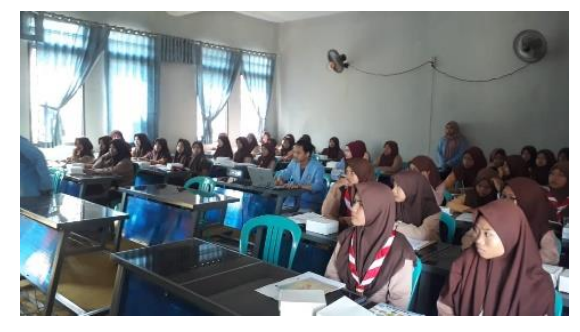

Gambar 3 Siswa SMK Palapa Ngoro antusias mendengarkan materi sosialisasi

\section{SIMPULAN}

Simpulan

SMK adalah saat ini adalah sekolah yang banyak diminati siswa, salah satunya Jurusan Akuntansi merupakan salah satu jurusan di SMK yang cukup banyak mendapatkan respon positif dari masyarakat. Pelaksanaan kegiatan berupa Sosialisasi dan penambahan informasi bidang dan jenis profesi akuntansi modern ini sangat diperlukan bagi siswa SMK jurusan akuntansi. Keragaman jenis -jenis akutansi dan profesi akuntansi akan membantu siswa untuk menentukan pilihan setelah siswa lulus dari SMK, dimana siswa bisa setelah lulus sekolah bisa langsung bekerja atau meneruskan pendidikan ke jenjang yang lebih tinggi sesuai minat yang diharapkan.

Saran

Literasi diperlukan bagi siswa SMK dalam menentukan minat dan profesi yang diinginkan setelah lulus. Saran yang bisa disampaikan perlunya penambahan literasi bagi siswa SMK, 
terutama jurusan Akuntansi, supaya siswa tidak mengalami kebingungan dalam menentukan minat dan profesi yang diharapkannya.

\section{DAFTAR PUSTAKA}

Hery. (2015). Pengantar Akuntansi, Comprehensive Edition. Jakarta: Grasindo.

Mustofa, A. \& Thobroni, M. (2011). Belajar dan Pembelajaran. Jakarta: Ar-ruzz Media

Nahartyo, E \& Utami, I. (2015). Riset Akuntansi Managemen: Telaah Tiga Perspektif. Jurnal Riset Manajemen Vol. 2, No. 1 .

Rombe, A., Poputra, A.T., \& Kalalo, M.Y.B. (2016). Analisis Sistem Kas Berbasis Akuntansi Keperilakuan Dalam Pelaporan Arus Kas Pada PT. Bank Sulutgo. Jurnal Berkala Ilmiah Efisiensi, Vol. 16 No. 01.

Rahayu, S., Sudaryono, E.A., \& Setiawan, D. (2003). Persepsi Mahasiswa Akuntansi Mengenai Faktor-Faktor Yang Mempengaruhi Pemilihan Karir. Surabaya, Simposium nasional akuntansi VI.

Suartana, I.W. (2010). Akuntansi keperilakuan Teori dan Implementasi. Yogyakarta: Penerbit Andi

Tompkins, G.E., \& Kenneth, H. (1991). Language Arts:Content and Teaching Strategis. New York: Max Well Macmillan International Publishing Group

Wardana \& Zamzam. (2014). Strategi Peningkatan Kemampuan Literasi Siswa di Madrasah. Jurnal Ilmiah "Widya Pustaka Pendidikan", 2 (3).

Weygant, J.J., Donald, E.K., \& Walter G.K. (1996). Accounting Principles, 4th Edition, John Wiley and Sons, Inc. 